\title{
EL IDEARIO CONSTITUCIONAL DE IGUALDAD Y LA DEFENSA DE LOS DERECHOS HUMANOS: LA CUESTIÓN DE LA HOMOSEXUALIDAD Y LA NO DISCRIMINACIÓN EN BRASIL
}

\author{
THE CONSTITUTIONAL IDEA OF EQUALITY AND THE DEFENCE OF HUMAN RIGHTS: THE \\ QUESTION OF HOMOSEXUALITY AND NON-DISCRIMINATION IN BRAZIL
}

\section{Douglas Verbicaro Soares}

Universidade Federal de Roraima, Boa Vista, RR, Brasil, douglas_verbicaro@yahoo.com.br

\begin{abstract}
Resumen: La investigación tiene como objetivo explicitar el ideario constitucional sobre la defensa de los Derechos Humanos en la sociedad brasileña, en especial sobre las personas homosexuales y la lucha contra la discriminación en Brasil. Por lo tanto, se ha realizado una investigación basada en fuentes bibliográficas que retratan la condena a la homosexualidad en el país. Para el estudio se ha empleado una metodología deductiva multidisciplinar, con relación al derecho, la historia, la sociología etcétera. Como indagaciones el estudio buscó algunas respuestas: ¿Qué establece la normativa brasileńa sobre la no discriminación? ¿Cómo es plasmada la igualdad en la Carta Magna? La investigación concluye manifestando ideales de prejuicios y discriminación a lo largo de los tiempos para las personas homosexuales en el país.
\end{abstract}

Palabras claves: Constitución. Homosexual. Violencia.

\begin{abstract}
The research aims to express the constitutional idea of the defense of Human Rights in Brazilian society, especially on gay people and the fight against discrimination in Brazil. Therefore, research has been conducted based on bibliographic sources that portrayed the condemnation of homosexuality in the country. A multidisciplinary deductive methodology has been used for the study, in relation to law, history, sociology and so on. As an inquiry, the study sought some answers: What establishes Brazilian non-discrimination regulations? How is equality embodied in Constitution? The research concludes by the existence of ideals of prejudice and discrimination, over time, for gay people in the country.
\end{abstract}

Keywords: Constitution. Homosexual. Violence.

\section{Introducción}

Los preceptos constitucionales previstos en el Ordenamiento Jurídico brasileño pasan, básicamente, por la idea que se tiene sobre la igualdad y la extensión de ese principio y fuente esencial del derecho positivo, que amplía sus influencias, incluso en las esferas internacionales de protección, de los asuntos que versan sobre los Derechos Humanos y la sexualidad humana (VERBICARO SOARES; CRUZ, 2018, p. 304) como derecho y merecedor de recibir un trato igualitario en relación a la protección y de efectividad 
en garantías para todos, es decir, incluyendo a los que son tratados como desiguales en el ámbito de una sociedad.

La visibilidad de ese ideario como una derecho fundamental, reconocido por el Estado Brasileńo, en su Carta Magna de 1988, y regente de todo el aparato judicial brasileño, refleja la incidencia de su principio constitucional como fundamento supremo que deberá ser seguido como fuente esencial en la protección, comprensión, aplicación y adecuación de todas las normas jurídicas a favor de la igualdad y de la realidad existente en sociedad.

Para corroborar con ese planteamiento jurídico, Borba (2013, p. 14) que al abordar el principio de la igualdad resalta que:

La tarea se muestra importante una vez que la igualdad al hacer parte de los textos constitucionales, el derecho a igualdad se hace incuestionable y sirve de parámetro de medida de la validez de los actos normativos del Estado. El desarrollo teórico de lo que se debe entender como el derecho a igualdad está permanentemente en construcción, una vez que los ojos de los defensores del ideal de la igualdad están siempre involucrados en la resolución de problemas que se originan en la convivencia humana, múltiplos y naturalmente volubles.

Con esas previsiones iniciales lo que se reivindica es el combate, motivados por la igualdad en prevenir el surgimiento de los denominados procesos que discriminen, que entenderemos como todas las formas que obstaculizaran el logro de la deseada igualdad entre las personas. Referencia teórica que será abordado en los próximos apartados.

Con base en esas premisas, el presente estudio tiene como objetivo generar la discusión social en el país sobre la diversidad sexual y, también, exponiendo algunos de los obstáculos que inviabilizan a la igualdad y el respeto a todas las personas.

Para la investigación ha sido empleada una metodología basada en fuentes bibliográficas multidisciplinares, es decir: el derecho, la historia, la psicología etcétera. El estudio tiene dos (2) apartados, más la introducción, consideraciones finales y referencias. El primero versa sobre las normativas brasileñas en cuanto a la no discriminación. El segundo retrata el modo en que la igualdad es expuesta en la Constitución brasileña.

De ese modo han sido realizadas algunas preguntas para el estudio: ¿Qué establece la normativa brasileña sobre la no discriminación? ¿Cómo es plasmada la igualdad en la Carta Magna?

\section{2 ¿Qué establece la normativa brasileńa sobre la no discriminación?}

Para la iniciación en ese apartado, hemos optado por la Carta Magna de Brasil, es decir, la Constitución Federal brasileña de 1988. En sus fundamentos se expresa: la búsqueda por una sociedad igualitaria y justa, esencia esa visibilizada en el preámbulo de la Constitución: asegurar el ejercicio de los derechos sociales e individuales, de libertad, seguridad, de bienestar, de desarrollo, de igualdad y justicia como valores supremos de una sociedad fraterna, pluralista y sin prejuicios. Es el destino fundamental del Estado democrático y de un ideal republicano. Curiosamente cabe al Poder Judiciario, según el propio ideario 
Douglas Verbicaro Soares

republicano brasileño, la misión de proteger los derechos individuales, inclusive los fundamentales, como bien aduce Ferreira Filho (2000), necesitando dos factores para actuar: ser llamado a intervenir por un legitimo interesado y la existencia de un litigio, una pretensión contrariada (FERREIRA FILHO, 2000, p. 115).

Se hace válido comentar que en el desarrollo de este estudio, se entendió que las conductas de prejuicio y discriminaciones hacia las personas homosexuales han tenido una relación directa con la visión que se tenía sobre sea orientación sexual a lo largo de la historia de la humanidad, haciendo que las personas que integran una determinada sociedad se manifiesten de una manera u otra, favorable o contraria a la realización de conductas con carácter de aislamiento excluyente (social, moral, político, económico, sexual, cultural, religioso, etcétera) (ENGUITA, 1993). Hechos estos que tienen directa relación con las justificaciones también utilizadas para la no integración o en los obstáculos generados que permitirían esa inclusión del colectivo homosexual en Brasil.

Se suma a esa idea la invisibilidad social de la homosexualidad, que con los preceptos negativos que le han sido atribuidos, a lo largo de los últimos siglos, han definido y reducido la visibilidad sobre el lema y la formación de un ideario limitado sobre lo que sería la homosexualidad, causas, efectos, características y otros factores relacionados con esa orientación sexual entre los animales, una vez que no es una práctica exclusiva de los humanos, evidenciada científicamente en otros animales como: delfines, ballenas, simios, pingüinos y otros.

En cuanto a la idea de invisibilidad, aportado en esa investigación, hizo que las personas homosexuales (hombres y mujeres) ocupasen una posición de segundo plano en sociedad, en mucho de los casos, que optaran por asumir una vida dupla, no verdadera, no asumiendo sus verdaderos sentimientos. En estos casos estarían los casamientos por conveniencia, que servirían como una fachada para el entorno social de un modelo heterosexual dominante, donde la familia estaría formada por personas con el sexo biológico distinto, entre un hombre y una mujer, con el propósito final de procreación familiar, tener hijos y moldar los roles según la voluntad de una sociedad basada en muchos casos, en un padrón patriarcal de superioridad de la figura del hombre como proveedor sobre la inferioridad de la mujer como cuidadora.

Según los relatos de Figueruelo (2012), al tratar el tema, nos aporta el alcance que las contribuciones más recientes por ejemplo del feminismo es el género:

En cuanto categoría social de análisis que surgió para explicar las desigualdades entre hombres y mujeres, colocando el acento en la idea de multiplicidad de identidades, con un enfoque globalizado y tiene en cuenta los rasgos y funciones psicológicos y socioculturales atribuidos a cada uno de los sexos en cada sociedad y en cualquier momento histórico. La problemática que encierran las relaciones de género destruye la idea del carácter natural de las mismas, porque lo femenino o lo masculino no hacen referencia al sexo de las personas, sino a las conductas consideradas femeninas o masculinas [...] la categoría de género puede ser entendida como una explicación sobre las formas que adquieren las relaciones entre los géneros en el marco de los procesos que operan dentro de la estructura social y cultural de las sociedades (FIGUERUELO, 2012, p. 61). 
Esas características siguen presentes en el mundo occidental fruto de costumbres seculares pasados de generación para generación. Y todo eso, alimentado por la idealización de la incompatibilidad (GUINEA, 2007, p. 53) de asumir una vida supuestamente normal frente a un patrón heteronormativo dominante socialmente, que una pareja homosexual sería incapaz de constituir una familia, de tener y cuidar de hijos. $\mathrm{El}$ inconveniente y el miedo social que las personal homosexuales al asumirse socialmente pueden motivar a otras personas a hacer lo mismo, podría generar un verdadero caos, donde representarían un supuesto riesgo para los demás en el medio social.

Todos estos argumentos hacen parte del tipificado por Guinea (2007) de un modo comparado al que ha sido extendido a la situación de las mujeres y nos sirve para aclarar la consigna de la homosexualidad en el medio social. La idealización de la incompatibilidad se proyecta en el miedo social que ciertos colectivos logren visualización y emancipación y son utilizados como herramientas que obstaculizaran la igualdad de trato, sea entre hombres y mujeres u otros colectivos, como puede ser el de los homosexuales en tener los mismos derechos que los heterosexuales.

Las personas homosexuales a lo largo de los tiempos lo tenían difícil. La opción estaría en adecuarse al modelo impuesto de la heterosexualidad, en ese sentido viviendo una vida para satisfacer la voluntad de los demás, o romper con los estereotipos creados y asumir los riesgos que podían venir con la segunda opción: acoso, violencia física, psíquica, muerte o un simple intento de vivir y amar a una persona del mismo sexo.

Por esta razón, nos hemos preocupado en indagar cómo serían esas muestras de afecto entre personas del mismo sexo, por ejemplo la simples manifestaciones de la orientación del deseo homosexual en sociedad y por así decir, la existencia de personas con esa manifestación del deseo hace que existan relaciones de afecto sentimentales (atracciones, pensamientos, prácticas sexuales) entre personas con el mismo sexo biológico, pues es válido recordar que las personas son libres para expresar sus sentimientos, amores, emociones y, también, tienen el derecho de compartir sus vida con quién creen podrán alcanzar la felicidad exteriorizando su amor (VERBICARO SOARES, 2012, p. 94).

\section{La Igualdad como pilar democrático y Derecho Fundamental: Reconocimiento por la Constitución Federal Brasileńa de 1988}

La Carta Magna de Brasil adopta el principio de la igualdad (VV.AA., 1988, p. 81-2) de derechos, donde, supuestamente, todos los ciudadanos tienen el derecho de trato idéntico por la ley según los criterios del Ordenamiento Jurídico del país (MORAES, 1999, p. 61).

En relación a las ideas presentadas, los instrumentos que obstaculizaran (BUSTOS, 2010, p. 235-6) el trato igualitario en la sociedad brasileńa se consolida en la existencia de acciones, conductas discriminatorias, motivadas por un desconocimiento general social sobre la cuestión de la orientación sexual, originadas en valores históricos culturales, predominantemente, conservadores.

Valores que impusieron la estipulación de roles de comportamientos y patrones a ser seguidos en la formación de un modelo donde el hombre, poseedor de una masculinidad pre-establecida, ejerce su 
Douglas Verbicaro Soares

superioridad hacia la mujer, interiorizada y sumisa a esos moldes patriarcales y que, cualquier desvío a esos idearios de masculino y del femenino, se caracterizaría como una violación a la estructura social formada y a un riesgo de ruptura de la supuesta normalización del comportamiento heterosexual sexista dominante.

La preservación de esos preceptos estructurales del dominio de la ignorancia colectiva y responsable por la exclusión, justifica que la mayoría de determinados colectivos vivan al margen de la sociedad, sin contar con el debido trato igualitario a los demás ciudadanos de la misma sociedad.

Borba (2013, p. 24) complementa ese posicionamiento racional añadiendo que, en relación al comportamiento sexual diferente de la heterosexualidad, es notoria su definición como anormal. A partir del instante en que se nota en el comportamiento sexual algo diverso de los patrones pre-establecidos, se inician los procedimientos de rechazo y de exclusión social. La idea de derecho a la igualdad debe de ser conjugada con el derecho a la diferencia, que no se mezcla con algún derecho a desigualdades sociales, en la medida en que las personas deben ser respetadas por sus características y opciones personales. Ese derecho englobaría el derecho a ser diferente, al reconocimiento de la identidad, y a la dignidad, sin ser estereotipado u obligado a adecuarse a un determinado patrón impuesto por la sociedad, lo que deberá ser combatido por el derecho.

Con base en estas ideas, el Ordenamiento Jurídico brasileño no es eficaz en el sentido de no tener norma jurídica que regule la igualdad de trato entre personas con una orientación diferente de la mayoritaria, que es la heterosexual, pues cuenta con el seguimiento mayor de la población humana. Pero antes de adentrarnos en estos temas se hace válida la citación de Carvalho (2011), que nos alude algunas consideraciones sobre la igualdad.

Entre sus argumentos que pueden ser utilizados en esta investigación dos serían las dimensiones de la igualdad:

Igualdad formal e igualdad material. Probablemente, todas las personas, aunque muchas no posean conocimientos de derecho y política y aunque lo hagan de forma intuitiva, consiguen percibir las diferencias entre la igualdad formal y material, las llamadas dimensiones de la igualdad. Esto ocurre porque se constata fácilmente que la igualdad introducida en las leyes como una prescripción, un deber-ser (igualdad formal o jurídica) no se confunde con el efectivo establecimiento de relaciones donde las personas deberían ser tratadas de forma igualitaria (igualdad material o sustancial) (CARVALHO, 2011, p. 41-2).

La igualdad mencionada sirve como ideario para la persecución de obstáculos que dificulten el trato igualitario entre los ciudadanos, de este modo, las variantes que se manifiesten contrarias a lo que establece la normativa de la Carta Magna de Brasil deberá ser interpretada, salvo justificación, de inconstitucional. Justificación esa que en su momento deberá ser objetiva y razonable, basándose en parámetros de valores aceptados, teniendo en cuenta una proporcionalidad en relación a la finalidad y efecto de las medidas a ser consideradas, es decir, la proporcionalidad mencionada llevada a cabo entre los medios a ser empleados y la finalidad a ser buscada. Además de respetar los derechos y las garantías constitucionales presentes en el Ordenamiento Jurídico de Brasil (MORAES, 1999, p. 62). 
En España, como caso análogo, Llamas (2012) preceptúa en uno de sus textos la viabilidad en considerar el principio de la igualdad como un principio general del derecho, haciendo alusión que principalmente en las últimas décadas, debido a las distintas reivindicaciones de grupos victimizados históricamente, citando al movimiento feminista junto con los continuos avances en la área social, se ha incluido en la agenda pública de ese país, la promoción de la igualdad entre hombres y mujeres en el aspecto del género (LLAMAS, 2012, p. 205). Aprovechamos para añadir a esa idea, que las mismas reivindicaciones por otros colectivos, entre ellos lo de la comunidad LGBT, lograron importantes conquistas en lo que se relaciona en materia de igualdad.

Moraes (1999) interpreta que: el principio de la igualdad consagrado por la CF/88 opera en dos planos distintos. De una parte, frente al legislador o al propio ejecutivo, en la edición de leyes, actos normativos etc., impidiendo de ese modo que se puedan crear tratos abusivos y diferenciados a personas que se encuentran en situaciones idénticas. En un segundo plano, esa igualdad se extiende a la interpretación del intérprete, en ese caso la autoridad pública, aplica las leyes y los actos normativos de un modo igualitario, sin tener en cuenta los motivos discriminadores.

De este modo, se puede notar que el precepto de la justificación también limita su existencia y no podrá ser empleado de modo absoluto, haciendo que los objetivos que limitan el principio de la igualdad se incorporan a la propia limitación del legislador (que no podrá al ejercer su función pública de edición de normas alejarse del principio mencionado supra bajo estar incumpliendo con los preceptos protegidos por la constitucionalidad), del intérprete o autoridad pública (que tienen prohibida la aplicación de las leyes o actos normativos en situaciones específicas con la sospecha de aumentar las diferencias entre los problemas enfrentados, así como también al particular) que no podrá basarse en conductas discriminatorias bajo penalización civil o penal según lo que establece el aparato jurídico nacional de Brasil (LLAMAS, 2012, p. 205).

También nos pareció oportuno en ese momento poner de relieve las consideraciones de MontalbánHuertas, manifiesta que: la resignificación del principio de igualdad como principio básico del Derecho moderno exige de los juristas un papel más activo y comprometido en la consecución de la igualdad efectiva entre los ciudadanos y en la erradicación de todas las formas de discriminación (MONTALBÁN-HUERTAS, 2012, p. 8). Ese principio está reconocido por la propia Declaración Universal de los Derechos Humanos, y que ese derechos extienden y protegen lo mismo en la visión de que cada persona en su dignidad es poseedora de esa igualdad junto a los demás. Del mismo modo en que la existencia de Instrumentos Internacionales de los DD.HH, sirven de inspiración para otros Estados y sus Ordenamientos Jurídicos Nacionales en fiscalizar el respeto a ese principio básico de la esencia humana y de los derechos que les son inherentes.

Brasil necesita todavía cumplir con un ideal de igualdad de todos sus ciudadanos reconociendo al colectivo de homosexuales haciendo realmente efectivo el acceso de esos ciudadanos a estos derechos. Se ha visto, en los últimos años, avances en estos aspectos, por ejemplo el reconocimiento de la unión estable homosexual a los mismos efectos que la heterosexual.

De acuerdo con Peces-Barba sobre la igualdad: 
Douglas Verbicaro Soares

Podríamos decir que la igualdad representa materializar los criterios para llevarse a cabo el valor de la solidaridad, creando las condiciones materiales para una libertad posible para todos, y contribuyendo a la seguridad con la satisfacción de necesidades a quien no puede hacerlos por su propio esfuerzo (PECES-BARBA, 1991, p. 242).

Bajo ese enfoque, es el Estado poseedor de un deber de implementar las medidas necesarias para la satisfacción de las necesidades de todos sus integrantes.

Validos son los comentarios de Ferreira Filho al definir el papel del Estado relacionados con los principios que les corresponde, conocidos como principios del Estado de Derecho como garantías constitucionales. Estado de Derecho ese basado, como bien defiende Ernst Böckenförde: que surge en la teoría del Estado del liberalismo de Alemania, la formación de un novedoso modelo de Estado, basado en la razón, de la conciencia, que gobierna de acuerdo con la voluntad general racional para incidir en la vida común en el bien común de esa sociedad.

De un modo muy pertinente la estructuración del Estado de Derecho y su relación con la propia idea de los Derechos Humanos, como un hilo que los relaciona, una vez que la esencia del Estado en la promoción de la libertad de cada integrante de la sociedad y la idea de igualdad que cada uno de esos individuos que componen el Estado, y el reconocimiento de los mismos como ciudadanos y que deben ser protegidos a favor de una armonía social y el interés común. De ese modo podemos entender que la protección de los Derechos Humanos, también incluye la postura asumida por el Estado de Derecho en permitir que los preceptos de igualdad y libertad sean garantizados a sus ciudadanos.

Se complementa con esa consideración la formación de un modelo heterosexual dominante que ha excluido a todos los que no se adecuaban a esos modelos históricos, culturales, y socialmente impuestos por la mayoría, en la evolución de la humanidad, lo que contribuyó de modo significativo para la exclusión social del colectivo de homosexuales en los días actuales.

Para algunos autores, la actual situación, principalmente la social en Brasil estaría marcada por una grande desigualdad social originada por un mal reparto de las riquezas, lo que implicaría en un aumento del carácter económico y jurídico entre las clases sociales brasileñas, lo que hace que la mayoría de los brasileńos acaben limitados y resignados en su media-ciudadanía, pues mientras se les concede por ejemplo el privilegio del voto, se les son denegados derechos básicos, como tener acceso a una salud digna, a un sistema educacional eficaz, a seguridad, al ocio, por no decir el propio reconocimiento de la dignidad humana (VERBICARO, 2015, p. 33).

En el mismo sentido se manifiesta Campilongo (2000), hablando del sistema político del país que muestra la ausencia de representación. De un lado, por la incapacidad de los partidos políticos de promover grandes cambios en una sociedad compleja, heterogénea y marcadas por cuestiones económicas, culturales y regionales tan diversas. Por otro lado, la falta de igual proporción de la participación de los Estados miembros de la Federación brasileña, los más desarrollados acaban siendo más representados, mientras los demás acaban siendo sobre presentados. En el ámbito cultural, Brasil pasa por una crisis sin precedentes en la historia del país. El descrédito en las Instituciones y la absoluta falta de ánimo en creer en posibilidades de cambios a corto plazo hacen que la sociedad brasileña adentre en un preocupante estado 
de crisis social y aumento de la marginalización general. Los problemas graves previamente existentes en cuanto a los derechos sociales de los brasileños solamente se intensifican. Las dificultades de control por parte de los Poderes Públicos, grandes casos de corrupción generalizada y el no respeto de la legalidad por el propio Estado, complementan la realidad precaria de la República Federativa de Brasil (CAMPILONGO, 2000, p. 53-4).

No obstante merece relevo la argumentación de que para una real efectividad de los Derechos Humanos y todo lo que implica, no solamente el crecimiento económico de un país o el aumento del Producto Interno Bruto, en ese caso de Brasil, repercuten en la compresión de que el país vive una condición de mejorada situación social, una vez que la buena época económica no siempre es capaz de reflejar la real situación social, con sus problemas enfrentados, desde un aumento significativo de la marginalización, hambruna, violencia generalizada. Los supuestos buenos augurios, en este caso para el área económica brasileña, acaban por dar una visión equivocada para un problema social cada vez más grande.

Ese posicionamiento sobre los problemas de tornar efectivos los Derechos Humanos, también, pueden ser encontrados en las razones, apuntadas por Sen (2002, p. 18), sobre las expansión de las libertades reales de las personas, que apunta que: a veces la ausencia de libertades subjetivas estarían relacionadas directamente con la pobreza económica, que roba de las personas la libertad en la satisfacción del hambre, de obtener una nutrición satisfactoria o de medicamentos para enfermedades tratables, la oportunidad de vestirse o de tener morada digna, de tener acceso a agua tratada y propia para el consumo humano u de un saneamiento básico vital.

También se visiona la privación de libertades de los ciudadanos en la carencia de los servicios públicos y de asistencia social, principalmente, relacionados con los temas que posibilitarían la manutención de la paz y del orden en una determinada sociedad. Del mismo modo en que las violaciones mencionadas pueden reflejarse en las áreas de la política o civil, en las hipótesis de regímenes autoritarios que imposibilitan la emancipación ciudadana (SEN, 2002, p. 18).

Para las alternativas sugeridas, quizás con la visión de que las acciones positivas logradas por las personas, de cierto modo, tienen influencia en las oportunidades económicas, libertades políticas, poderes sociales y por las condiciones habilitadoras como tener una buena salud, educación básica e incentivos y mejora en las iniciativas. Esas alternativas defendidas por Sen (2002) servirían para que las sociedades tuviesen políticas para ponerlas en práctica según las realidades internas de cada caso. De acuerdo con Sen:

Las disposiciones institucionales que proporcionan esas oportunidades son todavía influenciadas por el ejercicio de las libertades de las personas, mediante la libertad para participar de la decisión social y de la toma de las decisiones públicas que generen en progreso de esas oportunidades (SEN, 2002, p. 18).

Esta sería la alternativa propiciadora para el cambio de realidad en Brasil, que incluso lleva en su propia bandera el lema: Orden y Progreso, pero que de momento sigue sin los idearios defendidos, en una situación desfavorable en lo que tiene que ver con la efectividad de derechos, trato igualitario, participación ciudadana. 
Douglas Verbicaro Soares

Una de las causas problemáticas para lograr los objetivos buscados sería como defiende Verbicaro (2015, p. 33-4) la indolencia de la sociedad brasileña, donde la mayoría de los ciudadanos acaban asumiendo un papel individualista, donde cada uno busca sacar provecho según sus propios intereses, lo que aparta los individuos de realizar sus acciones participando del proceso ciudadano, es decir de ejercer sus deberes y exigir el cumplimiento de sus derechos. Lo que ocurre es justo el contrario, una inversión de los valores y en la materialización de una actitud política limitada y de poca o casi ninguna participación. El autor nos aclara que uno de los principales problemas para enfrentar la indolencia sería la identificación del enemigo, es decir, la estructura que facilita esa ausencia de voluntad participativa de los ciudadanos en cambiar la realidad problemática generalizada de la sociedad brasileña.

Los argumentos del autor supra citado van más lejos para representar los problemas estructurales vividos actualmente en Brasil:

Cuando se negligencia las virtudes que la solidaridad y la fraternidad cívicas pueden propiciar, se estará distanciando del proceso político, una vez que es preferible depositar en las manos de pocos la conducción de los temas de interés de todos. Estos pocos, no serán altruistas y se dudará que combatan su ganancia personal para pensar en el colectivo. Sus acciones serán marcadas por características personales, y por eso, escogerán mal las prioridades legislativas y del Gobierno, teniendo la certeza de la impunidad política, sin hablar de la jurídica, que ya hace mucho dominada por las enfermedades de un Judiciario poco independiente. Quién no conoce, no participa. Quién no participa no cambia. Quién no cambia, perpetúa la mala gestión del poder (ADÁN, 2011, p. 61-2).

La visión lastimada de la sociedad de Brasil explicitado por el jurista termina con la defensa de la idea de que la convicción que los representantes políticos del país de Sudamérica subvierten la democracia en un Gobierno caracterizado por la corrupción, por modelos diversos de políticas asistenciales que han dominado el país, sumándose la difusión de la ignorancia, responsables por un incremento de la pobreza social (VERBICARO, 2015, p. 35).

Para las desventajas de un Poder Judiciario lento y enfermizo, Bueno (2005) aclara que cuando el propio Poder Público está en Juicio, la efectividad, es decir la producción de resultados concretos y rápidos para aquel que, con alguna buena proporción de razón, busca amparo en el Poder Judiciario, lo del derecho procesal público es la no efectividad, creada por la creación de obstáculos, dificultades de las más variadas especies para el particular. La no efectividad por la eliminación pura y simple, de determinadas categorías e institutos procesales para cuando el Poder Público está en Juicio. Reglas procesales que son creadas para una de las partes solamente, hiriendo de muerte el principio del debido proceso legal. Todo para que el proceso tarde más de los que establezcan las leyes de la reforma, atendiendo al reclamo de la sociedad brasileña, quiere tolerar (BUENO, 2005, p. XVII).

Añadiremos a estos preceptos la visión de Sen al hablar del desarrollo como un proceso de expansión de las libertades reales de que disponen las personas y los ciudadanos en tener esas libertades. Para Sen: $e l$ enfoque en las libertades humanas contrasta con visiones más restrictas del desarrollo, como las que se identifican desarrollo con el crecimiento del Producto Nacional Bruto (PNB). Así como con el aumento de las rentas de las personas, la industrialización, los avances en tecnología o modernización social (SEN, 2002, p. 33-4). 
De este modo las ideas del autor indio enfocan que no sólo debe tomarse el crecimiento económico para cambiar los temas de las libertades de los ciudadanos de un país, sino que se debe tener también en cuenta distintos parámetros que también merecen relevo, como por ejemplo: el crecimiento del PNB, las rentas individuales, mejora en los temas sociales como la educación, la salud. Además de la efectividad de los derechos civiles de los ciudadanos, la libertad que tienen las personas en participar de modo libre de discusiones y de averiguar las materias relacionadas con el Poder Público de un Estado. Para lograr el desarrollo, es necesario la retirada de obstáculos que privan la libertad buscada, es decir, combatir la pobreza y la tiranía, la carencia de oportunidades económicas, la negligencia de los servicios públicos y la intolerancia o la interferencia excesiva de los Estados represivos (SEN, 2002, p. 17-8).

El autor defendía el relevo del Estado en la protección de valor básicos, como podrían ser la vida, la seguridad de sus ciudadanos, ese ideario protector se ha mantenido a lo largo de la evolución histórica de las sociedades y en muchos textos constitucionales esa esencia se mantuvo prácticamente inalterada y la positivación de eses valores, en la CF/88 de Brasil, por ejemplo siguen, actualmente en un conflicto en relación a la crisis generalizada que vive el país, principalmente en los temas que están relacionados con la protección y efectividad de derechos a las personas homosexuales.

Todos los días se manifiestan casos de agresiones y violaciones de derechos de un grupo que sigue en situación de desigualdad social, desde el tema de la protección, de vivir de un modo seguro. Un número considerable de ciudadanos brasileños homosexuales son victimizados, agredidos y asesinados por tener una orientación sexual distinta de la mayoría (la heterosexual) (VERBICARO SOARES, 2019, p. 155-6).

Por su parte, los entes públicos muestran una omisión gigantesca para cambiar esa realidad, desde el trato negligente de los cuerpos de seguridad públicos (comisarías de policía, fiscalías) y el propio Poder Público, por medio del Poder Judiciario, con sus funcionarios y jueces que no hacen caso al respeto de los casos que involucran a las personas homosexuales. Incluso el Poder Legislativo que tarda en hacer efectiva la protección de ese colectivo vulnerable por medio de leyes y de un Ejecutivo, que se acuerda en sus promesas, durante el período electoral, de ilusionar a la sociedad con planos de gobierno, establecidos solamente en proyectos que no seguirán adelante con el fin de las elecciones.

Hechos esos que comprometen la falta de acción del Estado brasileño en respetar a los principios básicos defendidos en su Carta Magna, pues al no garantizar la seguridad de sus miembros, al no permitir un acceso o incorporación de ese grupo en el ámbito laboral, el hecho de no facilitar el acceso al sistema de salud público eficaz y otros, hace que el ideario de Hobbes se quede alejado de la realidad vivida en Brasil (LEÓN, 2014, p. 341-2). De este modo, de un modo lamentable todavía el Estado brasileño no es capaz de ofrecer a sus ciudadanos la seguridad necesaria para poner fin a la grande inseguridad que es vivida en el país, principalmente para el colectivo LGBT (lesbianas, gais, bisexuales y transgéneros), que ocupa el índice como uno de los más peligrosos para vivir (VERBICARO SOARES, 2019, p. 156).

De acuerdo con Comparato (2001, p. 20) la influencia de Kant fue relevante para el desarrollo de los principios de los derechos universales de la persona humana. Según el autor:

Kant observó que solamente el ser racional tiene la facultad de actuar según la representación de leyes y principios, solamente un ser racional tiene voluntad, que 
Douglas Verbicaro Soares

representa una especie de la razón denominada razón práctica y que las reglas jurídicas a las cuales los hombres pasan a seguir, deberán ser elaboradas por los miembros de la asociación (VERBICARO SOARES, 2011, p. 38).

Ese ideario se plasma en la manifestación de que el hombre no existe como medio para su propia finalidad, pero que existe como un fin en sí mismo, es decir: todo el hombre tiene como un fin natural la realización de su concepción, que no basta al hombre el deber negativo de no perjudicar a alguien, pero, incluso, tiene el deber positivo de trabajar para la felicidad de los demás en sociedad. Ese raciocinio ha influido en el reconocimiento de derechos para la creación de políticas públicas de contenido económico y social (COMPARATO, 2001, p. 20), pero Brasil sigue en situación de desventaja en ese reconocimiento de derechos.

Bajo ese punto de vista, Brasil en su ideario democrático, peca por presentar un cuadro de descrédito de la sociedad, que ha dado paso a la formación de una sociedad despreocupada con su propia participación ciudadana y de lucha por cambios estructurales. Los momentos históricos de reivindicaciones contra la dictadura militar o más reciente los procesos de impeachment de los presidentes destituidos del poder Fernando Collor de Melo y Dilma Rousseff, han quedado en eso y que, últimamente, poco motivan los cambios democráticos necesarios para la construcción de un país con una efectiva y real igualdad de trato entre sus miembros.

Lo que se nota es una costumbre temeraria y preocupante de los brasileńos en permitir la degeneración de sus derechos, como resalta Verbicaro (2015):

Pues a la sociedad no se molesta más con no respeto a la condición humana, cuando por ejemplo, el individuo es sometido a un Sistema Único de Salud que se muestra indiferente a las interminables colas y a los rechazos en la atención en los hospitales públicos [...] desvíos de los recursos públicos, fraudes en licitaciones, sin cualquier tipo de sanción para sus criminosos, sea en el ámbito político, jurídico, sea por el propio Poder Legislativo en su lentitud y formalismo extremo del Judiciario en la aplicación de la Ley (VERBICARO, 2015, p. 35-6).

Como respuesta a estos problemas usaremos un ejemplo de actitud para cambiar esa realidad, que podría ser el propio uso responsable del voto de sus ciudadanos, pero que al final, acaba siendo la manifestación de un acto obligatorio que no hace jus a esa característica de ejercer la ciudadanía. La gran cantidad de escándalos, en el ámbito político acaban alejando a los ciudadanos de participar en el proceso electoral, de buscar la motivación de los representantes políticos de esa misma sociedad, lo que refleja en los últimos tiempos un aumento de los votos que son nulos o anulados, que demuestran un descontento general por ese derecho indispensable para el ideario democrático.

Para el cierre de estos argumentos se utilizarán las ideas de Santos Souza, que al aducir sobre la definida como razón perezosa (SOUSA SANTOS, 2000, p. 40) y complementada por Verbicaro (2015, p. 36), incluye a esa terminología a la pérdida de la propia autoestima del ciudadano y de su voluntad esencial en el momento en que no se siente como parte integradora del grupo. De este modo, los resultados incidirán en su alejamiento poco a poco de sus deberes y no reivindicando sus derechos. 
Otros autores se han manifestado dando relevo a la ciudadanía como un proceso indispensable para los cambios y respeto a los valores democráticos. Guinea (2007, p. 19) afirma que la polis democrática, se fundamenta sobre la igualdad. El criterio de participación y promoción politica y de su legitimación ya no es la sangre, sino la igualdad natural de los seres humanos. Para la autora, la visión de una sociedad construida sin lazos de sangre pero con el objetivo de ser una asociación contractual, dotada de individuos libres e iguales, bajo los pilares de una socialización entre sus miembros: inter-comunicación de sus discursos, inter-actuación e inter-ordenación con el mundo, con sujetos que sólo deben tener en cuenta su conciencia para la elaboración de una meta política que plasme el colectivo, el solidario y lo igualitario, visibilizando el instrumento de la ciudadanía real como un proceso en continuo desarrollo.

Evitar eses hechos es una labor indispensable, principalmente para aquellos que tienen más complicada la superación de sus situaciones de vulnerabilidad social. Por esta razón, es necesaria la defensa racional en que nadie debe ser privado de sus derechos motivados por la orientación sexual, en ese caso, la homosexual.

Para corroborar con ese raciocinio se cita el voto del Ministro Celso de Mello del Supremo Tribunal Federal de Brasil en relación al reconocimiento de la unión estable a las parejas homosexuales con los mismos derechos a los heterosexuales (JUSBRASIL, 2020).

En ese sentido como bien nos aclara Bonfim:

El cambio de paradigma en el derecho brasileño es total a la vista de la evolución histórica-jurídica, en la medida en que la condición de homosexual ha pasado de la condena a la muerte y confisco de los bienes a la posibilidad de institución de la unión estable homosexual, la conversión de esa al casamiento o incluso de contraer esa institución en un notario de registro civil (ANDRADE DO BOMFIM, 2011, p. 88).

Sin duda eses cambios en la última década en el Ordenamiento Jurídico de Brasil demuestran ciertos esfuerzos para el respeto de los mismos derechos a las personas con una orientación sexual homosexual en los parámetros de mayor reconocimiento del trato igualitario.

\section{Consideraciones finales}

Para los problemas enfrentados es importante fiscalizar el cumplimiento del principio de la igualdad ya mencionado en ese estudio, justamente para evitar los casos de discriminación a los ciudadanos brasileños que tienen una orientación sexual homosexual. Además, para que no sean víctimas de una estructura societaria basada en un modelo heterosexuales dominantes. Para estos casos, el Estado brasileño (de un modo conjunto entre sus 3 Poderes) deberá estar atento a las situaciones de desigualdad y adecuar sus políticas, e incluso, a cambiar sus normas discriminadoras para combatir un trato desigual y permitir la inclusión de los grupos en verdadera situación de exclusión.

El paso dado por el Supremo Tribunal Federal de Brasil, ha visibilizado la efectiva materialización de ciertos principios básicos del derecho, como por ejemplo el de la igualdad, la libertad personal de cada persona, la autonomía individual, la vida privada y el respeto sobre todo de la dignidad humana y preservación de los Derechos Humanos para las personas homosexuales. Los hechos marcan una evolución 
Douglas Verbicaro Soares

historia en la sociedad del país suramericano, rompiendo con estructuras conservadoras que han estado presentes en la historia brasileña y profundamente sometida a patrones culturales, religiosos, económicos que obstaculizaban la vida de un colectivo social vulnerable por motivo de una orientación sexual diversa de la mayoría, la heterosexual.

Válido nos pareció el posicionamiento del Ministro Mello, que al recordar que es necesario el discurso de cambio de paradigma, lucha contra al trato excluyente de grupos victimizados socialmente, en ese caso lo de los homosexuales y tomada de una nueva concepción de derecho, basada en una nueva interpretación del mundo a superar los desafíos que exigen esos cambios exigidos por preceptos democráticos. Cambios estos visibilizados por medio de políticas del Estado un orden jurídico con características inclusivas, en condición de respeto a valores esenciales del derecho como la dignidad humana, la libertad, la autodeterminación, igualdad, pluralismo, la intimidad, no discriminación y, principalmente, en la búsqueda por la felicidad.

De ese modo es cristalina la no constitucionalidad, es decir que se opone a la Carta Magna brasileña los actos que condenen, perjudiquen, materialicen cualquier tipo de acoso, dificulte el acceso a las personas homosexuales a los temas relacionados con la esfera social, económica, política, jurídica etc. Lo que nos llama la atención es que la cuestión enfrentada en este estudio involucra un lema básico de las relaciones humanas, donde cada uno, de un modo libre, debería buscar su propia felicidad y de demonstrar sus afectos, su amor y de tener la seguridad de poder hacerlo.

Es importante recordar que en los casos más novedosos el STF viene cambiando su postura y en el pleno desarrollo de su función constitucional pronunciándose en el sentido de reconocer los derechos de las minorías, preservando: los mandamientos constitucionales, la intangibilidad de derechos, intereses $y$ valores que identifican los grupos minoritarios en situación de vulnerabilidad diversa (JUSBRASIL, 2020) social, económica, política, jurídica etc., que por esa condición, se tornan victimizados por los prejuicios, discriminaciones, lo que les aparta de la sociedad y les pone en situación o en riesgo de exclusión en Brasil.

\section{Referencias}

ADÁN, Antonio. "Derechos humanos, pobreza y ayuda al desarrollo" en: VV.AA.: Os Direitos Humanos. Unha Ollada Múltiple. Servizo de Publicacións e Intercambio Científico. Santiago de Compostela, España, 2011.

ANDRADE DO BOMFIM, Silvano. "Homossexualidad, Direito e Religião: pena de morte à união estável. A criminalização da homofobia e seus reflexos na liberdade religiosa," en: Revista Brasileira de Direito Constitucional - RBDC, n. 18 - jul./dez. Brasil, 2011.

BORBA, Felipe. O crime militar de pederastia e a discriminaçâo contra os homossexuais: Uma investigação do tipo penal do artigo 235 do CPM à luz do direito da antidiscriminaçâo. Mestrado Acadêmico em Direito do Centro Universitário Ritter dos Reis. Porto Alegre, Brasil, 2013. 
BUENO, Cassio. O Poder Público em Juizzo. 3a Edição. Editora Saraiva. São Paulo, Brasil, 2005.

BUSTOS, María Ángeles. "La transcendencia del sistema de función pública en el desarrollo de la igualdad”. In: RUIZ, Manuela Mora. (Dir.) Formación y objeto del Derecho antidiscriminatorio de género: perspectiva sistemática de la igualdad desde el Derecho público. Barcelona, Espanha: Atelier, pp. 235-54, 2010.

CAMPILONGO, Celso. O direito na sociedade complexa. Editora Max Limonad. São Paulo, Brasil, 2000, pp. 53-6.

CARVALHO, Fábio. Acceso igualitario a la función pública: consideraciones sobre el modelo español de selección de los funcionarios. Editora Juruá, Curitiba, Brasil, 2011.

COMPARATO, Fábio. A Afirmação Histórica dos Direitos Humanos. Editora Saraiva. São Paulo, Brasil, 2001, p. 20.

ENGUITA, Mariano. Las desigualdades de clase, género, etnia y ciudadanía ante la educación. Sociología de la Educación, Universitat de les Illes Balears, España, 1993.

FERREIRA FILHO, Manoel. Direitos humanos fundamentais. Editora Saraiva. 4a Edição. São Paulo, Brasil, 2000.

FIGUERUELO, Ángela. "Introducción de la perspectiva de género en el derecho penal” en: VV.AA.: Igualdad. Retos para el siglo XXI. Andavira Editora. Santiago de Compostela, España, 2012.

GUINEA, Marta. Mujeres y ciudadanas: artesanas invisibilizadas de derechos humanos. Universidad de Deusto. Bilbao, País Vasco, España, 2007.

JUSBRASIL. Min. Celso de Mello - Excepcional voto na ADI 4277. Disponible en: <http://iab.jusbrasil. com.br/noticias/100329388/min-celso-de-mello-excepcional-voto-na-adi-4277>. Acceso en: 29 ago. 2020 .

LEÓN, Fernando. “Derechos Humanos y Diversidad Sexual: Contexto General”. Quinta Parte en VVAA.: Manual Derechos Humanos de los Grupos Vulnerables. DHES - Red Derechos Humanos y Educación Superior. Universidade Federal do Pará. Belém, Brasil, 2014.

LLAMAS, Miguel. "La igualdad de género como principio ético y de conducta en las administraciones públicas", en: VV.AA.: Igualdad. Retos para el siglo XXI. Andavira Editora. Santiago de Compostela, España, 2012.

MONTALBÁN-HUERTAS, Inmaculada. "Prólogo", en: VVAA: Igualdad. Retos para el siglo XXI. Andavira Editora. Santiago de Compostela, España, 2012.

MORAES, Alexandre. Direito Constitucional. 5a Edição. Editora Atlas S.A., São Paulo, Brasil, 1999. 
Douglas Verbicaro Soares

PECES-BARBA, Gregorio. Curso de Derechos Fundamentales (I) Teoria General. Editorial Eudema. Madrid, España, 1991.

SEN, Amartya. Desenvolvimento como liberdade. Prêmio Nobel Companhia das Letras. São Paulo, Brasil, 2002.

SOUSA SANTOS, Boaventura. Crítica da Razão Indolente: contra o desperdício da experiência. 2a Edição. Ediçôes Afrontamento. Porto, Portugal, 2000.

VERBICARO, Dennis. Consumo e Cidadania: A defesa processual coletiva do consumidor como uma expressáo da solidariedade. Tesis Doctoral. Universidad de Salamanca: Programa de Doctorado Pasado y presente de los Derechos Humanos, Salamanca, España, 2015.

VERBICARO SOARES, Douglas. Homossexualidade e Forças Armadas. A busca pela efetividade dos Direitos Humanos no Brasil. Tesina del Programa de Doctorado Pasado y Presente de los Derechos Humanos, Universidad de Salamanca - USAL, Salamanca, España, 2011, 233 p.

VERBICARO SOARES, Douglas. Las mujeres y las personas homosexuales en las Fuerzas Armadas. Especial referencia a las FFAA Brasileñas. Trabajo fin de Máster. Programa Estudios Interdisciplinares de Género y Políticas de Igualdade. Faculdade de Direito. Universidade de Salamanca - USAL, Salamanca, España, 2012. 146 p.

VERBICARO SOARES, Douglas. "O estudo da orientação homossexual pensado nos Direitos Humanos e na sociedade brasileira”. In.: Revista Bagoas - Estudos gays, gênero \& sexualidades. V. 13, no 20, pp.121-163, 2019.

VERBICARO SOARES, Douglas; CRUZ, Rivetla. "Históricas influências artísticas na formação de ideários sobre a orientação homossexual na sociedade brasileira”. In.: Revista Pensamento Jurídico FADISP. Vol.12, no 2, jul./dez., pp. 281-307, 2018.

VV.AA. Libertad, Igualdad y Derecho. Editorial Ariel. Barcelona, España, 1988. 